\title{
Erratum to: Annual Conference of the British Society of Neuroradiologists
}

Hilton Hotel, Belfast - October 10 and 11, 2014

The Publisher

(C) Springer-Verlag Berlin Heidelberg 2014

Erratum to: Neuroradiology (2014) 56:1007-1020

DOI 10.1007/s00234-014-1446-8

The original publication of this article does not contain information about the conference these Abstracts belong to. It should be:

Annual Conference of the British Society of Neuroradiologists Hilton Hotel, Belfast - October 10 and 11, 2014

The online version of the original article can be found at $\mathrm{http}: / \mathrm{dx}$.doi.org/ 10.1007/s00234-014-1446-8.

The Publisher $(\bowtie)$

www.springer.com 